\title{
Large fractionation of calcium isotopes during cave-analogue calcium
} carbonate growth

\author{
L.M. Reynard, ${ }^{a, b}$ C.C. Day ${ }^{a}$ and G.M. Henderson ${ }^{a}$
}

${ }^{a}$ Department of Earth Sciences, University of Oxford, South Parks Road, Oxford, UK, OX1 $3 \mathrm{AN}$

${ }^{b}$ Research Laboratory for Archaeology and the History of Art, University of Oxford, Dyson Perrins Building, South Parks Road, Oxford, UK, OX1 3QY

\section{Abstract}

We have measured $\delta^{44 / 42} \mathrm{Ca}$ of laboratory-precipitated calcite grown in an experimental setup that closely replicates stalagmite formation. Calcium solutions were dripped onto two different substrates in tightly-controlled conditions and calcite precipitated due to rapid $\mathrm{CO}_{2}$ degassing. With seeded glass slides as the substrate, we observe a Ca isotope ratio in the calcite which is $\sim 0.5 \%$ per amu lower than that in the growth solution. This fractionation is generally almost twice that observed in previously published calcite growth experiments and indicates a large kinetic effect on Ca isotopes in the stalagmite growth environment. The precipitate forming near the spot where the drip lands shows slightly greater solution-to-precipitate fractionation than calcite further from the drip reflecting a decrease in this kinetic fractionation as precipitation continues. We interpret these results in the context of the model of Fantle and DePaolo (2007) which involves surface entrapment of light Ca isotopes to decrease calcite $\delta^{44 / 42} \mathrm{Ca}$, and depletion of $\mathrm{Ca}$ from the solution in the direct vicinity of the growing calcite to increase calcite $\delta^{44 / 42} \mathrm{Ca}$. In the stalagmite setting, the second of these effects is minimized so that calcite Ca isotope ratios are unusually light. This interpretation suggests that stalagmite Ca isotope ratios should decrease with the saturation state of the drip water (i.e. with the growth rate of calcite). Ca isotopes might therefore allow reconstruction of surface entrapment of trace metals and isotopes 
more generally and might, for instance, allow an assessment of the appropriate relationship between oxygen isotope fractionation and temperature for periods of past growth in stalagmites.

\section{INTRODUCTION}

Calcium carbonates forming in cave settings are increasingly being used as recorders of past climate change (e.g. Bar-Mathews and Ayalon, 1997; Fleitmann et al., 2003; Hu et al., 2008; Wang et al., 2001). Stalagmites can be accurately dated with U-Th techniques, and the chemical variations along their growth axis then used to reconstruct aspects of the past environment. Although trace-element ratios are sometimes used for this purpose (Fairchild and Treble, 2009) by far the most commonly applied paleoproxies are the isotope-ratios of oxygen and carbon (McDermott, 2004). Fractionation in both of these isotope systems is, however, influenced by a number of variables in the cave setting (Lachniet, 2009) so that it is difficult to unambiguously assign measured changes in isotope ratios to specific environmental changes. A potential approach to solve this problem is to use multiple proxies to enable various environmental controls to be separated from one another (e.g. Johnson et al., 2006; Ayalon et al., 1999; Fairchild and Treble, 2009). This motivates development and calibration of new proxies in cave carbonates, including this study.

Unlike the other two major constituents of $\mathrm{CaCO}_{3}$, calcium has so far escaped dedicated research into its isotopic controls in the cave setting. This contribution presents such a study, based on carbonates grown in carefully controlled lab conditions, and focuses on the potential of Ca isotopes to help understand kinetic fractionation in the cave setting. We set this work in the context of a growing body of work assessing the fractionation of Ca isotopes during carbonate growth more generally.

Calcium isotopes have been measured in an increasing range of substrates, including rocks (Skulan et al., 1997; Tipper et al., 2006, 2008; Amini et al., 2009; Holmden, 2009), rivers (Schmitt et al., 2003; Tipper et al., 2006; Chu et al., 2006; Tipper et al., 2008; Jacobson and Holmden, 2008; Cenki-Tok et al., 2009), soils (Tipper et al., 2006; Ewing et al., 2008), vegetation (Chu et al., 2006; Page et al., 2008; Cenki-Tok et al., 2009), marine biogenic precipitates (Zhu 
and Macdougall, 1998; Nägler et al., 2000; Fantle and DePaolo, 2005; Sime et al., 2005, 2007; Farkaš et al., 2007a,b) and inorganic precipitates (Fantle and DePaolo, 2007; Griffith et al., 2008; Ewing et al., 2008; Teichert et al., 2009), animal soft tissues (Skulan and DePaolo, 1999; Skulan et al., 2007; Hirata et al., 2008) and bone apatite (Skulan et al., 1997; Skulan and DePaolo, 1999; Clementz et al., 2003; Chu et al., 2006; Reynard et al., 2010). Several synthetic calcium carbonate precipitation experiments have been undertaken to understand Ca fractionation during mineral growth (Marriott et al., 2004; Lemarchand et al., 2004; Gussone et al., 2005; Tang et al., 2008).

All of these previous growth experiments have been "beaker-type" experiments, where calcite (or aragonite, in the case of Gussone et al., 2005) is precipitated from a calcium-containing solution in a modified beaker. For example, Tang et al. (2008) and Gussone et al. (2005) use a stirred outer solution of $\mathrm{Ca}^{2+}, \mathrm{Cl}^{-}, \mathrm{Sr}^{2+}$, and $\mathrm{NH}_{4}^{+}$ions, and allow $\mathrm{HCO}_{3}^{-}$to diffuse through a membrane into this solution from a second beaker held within the outer vessel. Lemarchand et al. (2004) hold a beaker of $\mathrm{Ca}^{2+}, \mathrm{Cl}^{-}$, and $\mathrm{NH}_{4}^{+}$solution in a larger sealed volume with an atmosphere rich in $\mathrm{NH}_{3}$ and $\mathrm{CO}_{2}$ gas. The $\mathrm{CO}_{2}$ diffuses into the solution to produce the calcite. They vary the experiment between unstirred and stirred solutions. Marriott et al. (2004) use an agitated beaker of $\mathrm{Ca}^{2+}$ and $\mathrm{Cl}^{-}$(together with a range of trace elements), into which they pump $\mathrm{NaHCO}_{3}$ and $\mathrm{CaCl}_{2}$ at a constant input rate, while bubbling air through the vessel to maintain a constant $\mathrm{p}_{\mathrm{CO}_{2}}$.

These laboratory experiments have all derived a fractionation factor $(\alpha)$ for precipitation of calcium carbonates of $<1$, with $\delta^{44 / 42} \mathrm{Ca}$ values in resulting calcites typically $\sim 0.4 \%$ o $\left(\delta^{44 / 40} \mathrm{Ca}\right.$ $\sim 0.8 \%$ ) isotopically lighter than the growth solution. Fractionation in aragonite is greater, with $\delta^{44 / 40} \mathrm{Ca}$ up to $1.9 \%$ lower than the solution (Gussone et al., 2003). These experiments suggest a weak temperature dependence of fractionation (e.g. Marriott et al., 2004; Tang et al., 2008) with $\alpha$ approaching 1 as temperature increases. These laboratory experiments produce differing results, however, in the relationships between growth rate and $\delta^{44 / 40} \mathrm{Ca}$. Lemarchand et al. (2004) found that $\delta^{44 / 40} \mathrm{Ca}$ of the crystal increases towards the growth solution value (i.e. less fractionation) as growth rate increases, while Tang et al. (2008) found the opposite. These 
experiments therefore indicate that more than one kinetic process is influencing $\mathrm{Ca}$ isotope fractionation. Fantle and DePaolo (2007) proposed a model involving depletion of Ca in the interface region around the growing precipitate and surface entrapment of ${ }^{40} \mathrm{Ca}$ on the mineral surface. This model predicts maximum kinetic fractionation at intermediate growth rates, where the surface entrapment of isotopically lighter $\mathrm{Ca}$ is not limited by $\mathrm{Ca}$ depletion in the interface region.

Here we expand these laboratory efforts and test the models of calcium isotope fractionation in an experiment designed to replicate calcite precipitation during stalagmite growth rather than a marine setting. Our apparatus drips solutions at a constant and controllable temperature and rate onto a substrate consisting of a glass plate seeded with calcium carbonate or an upturned evaporating dish. We report the calcium isotope ratios $\left(\delta^{44 / 42} \mathrm{Ca}\right)$ of the resultant precipitates and initial solutions, and assess the kinetic controls on calcium isotope fractionation and the potential uses of $\mathrm{Ca}$ isotopes in the cave setting and elsewhere.

\section{EXPERIMENTAL METHODS}

The apparatus and experimental conditions used to grow calcite in these experiments are described in detail in Day and Henderson (2011), and we give only a brief summary here. A constant temperature water bath holds two large containers (Figure 1). A first container (the dissolution container) contains the stirred calcium solution in a high $\mathrm{pCO}_{2}$ environment whilst a second one (the precipitation container) has low $\mathrm{pCO}_{2}$ for calcite precipitation. Solution is pumped from the dissolution container to the precipitation container using a peristaltic pump which allows for accurate drip rate control.

Two sets of experiments were undertaken. In the first, referred to as "evaporating dish experiments", an inverted evaporating dish was used as the substrate, and the calcium carbonate solution was dripped onto the top of the dish. No seed calcium carbonate was used but the glass surface was frosted to aid nucleation. The atmosphere of the dissolution container was $100 \% \mathrm{CO}_{2}$, whilst the atmosphere of the precipitation container was maintained below 2,500 ppm $\mathrm{CO}_{2}$. The drip rate was $13.7 \mathrm{drips} / \mathrm{min}(0.06 \mathrm{~mL} / \mathrm{drip})$. The experiments were performed 
across a range of temperatures from 10 to $30^{\circ} \mathrm{C}$. This growth setup fails to accurately mimic the cave environment in several ways (e.g. $\mathrm{CO}_{2}$ concentration, lack of seeds) but is reported here for completeness.

These problems were corrected in the second set of experiments, referred to as "glass slide experiments", in which a glass microscope slide was seeded with calcium carbonate and placed at a $12^{\circ}$ angle under the drip (Figure 2). Based on in-situ scanning electron microscope (SEM) imagery, the seed material is dominated by well-defined calcite rhombs, the largest of which approach $100 \mu \mathrm{m}$ in length, and also contains some aragonite needles and perhaps some minor vaterite (Figure 3). Using a nucleation seed in the stalagmite growth experiment that consists of a mixture of calcium carbonate polymorphs is favourable to using no seed, simple glass frosting (Mickler et al., 2006) or artificial substrates such as glass fiber (Wiedner et al., 2008) because seeded growth is more representative of natural growth conditions; more specifically because the presence of seed material closely matched to the precipitating material reduces the energy barrier required for solid precipitation to occur (Steefel and Van Cappellen, 1990; Stumm and Morgan, 1996; Lin and Singer, 2005). The seed calcium carbonate was doped with Eu to allow subsequent correction for Ca from the seed when measuring $\delta^{44 / 42} \mathrm{Ca}$, with Eu/Ca of typically $1.4 \times 10^{-6}$ (atom ratio). Given there was no $\mathrm{Eu}$ in the drip solution, we calculated the seed proportion in the final precipitate from seed proportion $=(E u / C a)_{\text {seed }+ \text { ppt }} /(E u / C a)_{\text {seed }}$. The atmosphere of the dissolution chamber was maintained at 20,000 ppm $\mathrm{CO}_{2}$, whilst the precipitation chamber was maintained below 2,500 $\mathrm{ppm}^{\mathrm{CO}_{2}}$. Experiments were performed across a range of temperatures from 7 to $35^{\circ} \mathrm{C}$ and for each temperature, samples were precipitated at three separate drip rates $(1.6,5.8$, and 10.4 drips per minute, $0.11 \mathrm{~mL} / \mathrm{drip})$.

The slide and dish are divided into several zones; we measure calcite from the top and ponded zone on the dish, and the splash zone and the ponded zone on the slide (Figure 2). We do not report precipitation rates, as we have no reliable way of measuring or estimating the surface area for calcium carbonate precipitation in these growth conditions.

The initial solutions used in the evaporating dish experiment contained a constant $6.7 \mathrm{mM}$ 
$\mathrm{Ca}$, with $100 \% \mathrm{CO}_{2}$ in the first vessel, resulting in a variable starting saturation index (SI) of -0.65 to 0 with changing temperature $\left(\mathrm{SI}=\log \Omega_{\text {calcite }}=\log \left(\left[\mathrm{Ca}^{2+}\right]\left[\mathrm{CO}_{3}^{2-}\right] / \mathrm{K}_{s p}\right)\right)$. The initial solution in the glass slide experiments was kept at a constant initial saturation index of 0.34 $\left(\Omega_{\text {calcite }}=2.19\right)$, with $2.4-4.0 \mathrm{mM} \mathrm{Ca}$ and $20,000 \mathrm{ppm} \mathrm{CO}_{2(g)}$ in the dissolution vessel. Full details of the composition of the initial solutions for the dish and plate experiments are given in Table 1. Table 2 compares these initial solution compositions with those from previous beaker-type experiments.

On arrival of this initial solution into the precipitation container there is a significant difference between beaker-type experiments imitating marine conditions with large solution thickness and these cave-analogue experiments with thin-film solutions on the stalactite/ stalagmite surface. In the cave setting, evolution of the solution chemistry is more dynamic due to rapid $\mathrm{CO}_{2}-$ degassing and subsequent carbonate precipitation. The calcite saturation ratios as solution flows down-plate in these cave-analogue experiments are therefore calculated from the kinetics of $\mathrm{CO}_{2(a q)}$-degassing and of calcite precipitation. We report this quantity as $\Omega_{\text {calcite_evolved, with }}$ calculation details in the Appendix.

Scanning electron microscope images were recorded of the calcium carbonate precipitated on the slides (Figure 3). The precipitate is primarily composed of calcite rhomboids; this is the case for all of the slides examined. Precipitated calcite was removed from the slide or evaporating dish, dissolved in dilute nitric acid solution and measured by mass spectrometry without any further preparation. Sr spiking experiments demonstrate that measurement of the mass 43.5 beam (corresponding to doubly-charged ${ }^{87} \mathrm{Sr}$ ) enables accurate correction for Sr interference up to relative beam sizes of mass $43.5 / 44$ of $4 \times 10^{-4}$. Above this value the correction becomes insufficiently precise to provide adequate precision on final $\delta^{44 / 42}$ Ca values. The $\mathrm{Sr}$ concentration in dilutions made from the precipitated calcite sample solutions was less than $15 \mathrm{ppb}$, so that chemical separation to remove doubly-charged Sr interferences was not required. The initial growth media have higher Sr concentrations, with a maximum $420 \mathrm{ppb}$. This is still below the threshold correctable by measurement of the mass 43.5 beam by a factor of 2. Nevertheless, the initial solutions were processed through $\mathrm{Sr}$ specific resin to separate $\mathrm{Sr}$ 
from Ca (Chu et al., 2006).

Calcium isotope ratios $\left({ }^{44} \mathrm{Ca} /{ }^{42} \mathrm{Ca}\right.$ and $\left.{ }^{43} \mathrm{Ca} /{ }^{42} \mathrm{Ca}\right)$ were measured on a multicollector-ICP-MS (Nu Instruments), with a desolvating nebulizer sample introduction system. The rf power was $1300 \mathrm{~W}$. Ratios were measured 120 times with 1 s integration time. Solutions were at $10 \pm 1$ ppm concentration, and the samples were measured with standard-sample bracketing, with NIST SRM915a as the reference material. A secondary elemental solution standard was measured before every unknown as another check on the data quality. A three-isotope plot $\left(\delta^{44 / 42} \mathrm{Ca}\right.$ v. $\left.\delta^{43 / 42} \mathrm{Ca}\right)$ was also used to reject outliers which were not within $0.17 \%$ of the 2:1 line. Our long-term external reproducibility (standard deviation of all measurements over several years) of mono-elemental calcium solutions and our in-house bone powder standard are similar. We have measured $\delta^{44 / 42} \mathrm{Ca}=0.36 \pm 0.11 \%$ and $\delta^{43 / 42} \mathrm{Ca}=0.19 \pm 0.15 \%$ o $(2 \mathrm{sd}, \mathrm{n}=154)$ for HPSnew (High Purity Standards Ca solution); $\delta^{44 / 42} \mathrm{Ca}=0.41 \pm 0.10 \%$ and $\delta^{43 / 42} \mathrm{Ca}=0.21$ $\pm 0.19 \%$ ( $2 \mathrm{sd}, \mathrm{n}=239)$ for Alfa (Alfa Ca solution); and $\delta^{44 / 42} \mathrm{Ca}=-0.41 \pm 0.13 \%$ and $\delta^{43 / 42} \mathrm{Ca}=$ $-0.21 \pm 0.13 \%$ o (2 sd, n=93) for the bone powder (archaeological cattle bone).

We have measured SRM $915 \mathrm{~b}$ as $\delta^{44 / 42} \mathrm{Ca}=0.43 \pm 0.17 \%$ and $\delta^{43 / 42} \mathrm{Ca}=0.21 \pm 0.15 \%$ o $(2 \mathrm{sd}$, $\mathrm{n}=38)$, and seawater $\delta^{44 / 42} \mathrm{Ca}=0.96 \pm 0.16 \%$ and $\delta^{43 / 42} \mathrm{Ca}=0.49 \pm 0.16 \%$ (2 sd, $\left.\mathrm{n}=13\right)$, in agreement with published measurements (SRM 915b: $\delta^{44 / 40} \mathrm{Ca}=0.72 \pm 0.04 \%$, Heuser and Eisenhauer, 2008; seawater: $\delta^{44 / 40} \mathrm{Ca}=1.88 \pm 0.04 \%$, Hippler et al., 2003).

We define $\Delta^{44 / 42} \mathrm{Ca}=\delta^{44 / 42} \mathrm{Ca}_{\text {precipitate }}-\delta^{44 / 42} \mathrm{Ca}_{\text {initial solution }}$ (and similarly in the more general case $\left.\Delta \mathrm{Ca}=\delta \mathrm{Ca}_{\text {precipitate }}-\delta \mathrm{Ca}_{\text {initial solution }}\right)$. This value is generally negative, because ${ }^{44} \mathrm{Ca}$ is preferentially held in solution compared to ${ }^{42} \mathrm{Ca}$, resulting in higher solution $\delta^{44 / 42} \mathrm{Ca}$ values.

\section{RESULTS}

The $\delta^{44 / 42} \mathrm{Ca}$ and $\delta^{43 / 42} \mathrm{Ca}$ values of precipitates, seeds, and initial solutions are given in Tables 3 and 4 .

The seed crystals were produced as a single batch for all experiments. The variability in the 
measured seed crystals reported in Table 3 is comparable to the measurement uncertainty, which suggests we have measured a single population of crystals. Given we did measure the seed crystals for each experiment, we report the individual measurements.

For the glass slide experiments the seed fraction and its isotope ratio were used to calculate the $\delta^{44 / 42} \mathrm{Ca}$ of pure precipitates and then the precipitate-to-initial solution offset $\left(\Delta^{44 / 42} \mathrm{Ca}\right)$ was computed.

To check analytical accuracy, we remeasured 7 of the precipitate solutions from the evaporating dish experiments in a different analytical session 5 months later, and the $\delta^{44 / 42} \mathrm{Ca}$ values from the two sets of measurements agree with a mean difference of $0.02 \%$, one standard deviation of $0.04 \%$, and a maximum difference of $0.10 \%$. The initial solutions for each experiment were made from the same stock calcite and the $\delta^{44 / 42} \mathrm{Ca}$ values agree with each other, with one standard deviation of the mean of $0.04 \%$ for both experiments. We are confident that we are accurately reporting the $\delta^{44 / 42} \mathrm{Ca}$ values of the initial solutions and precipitates.

For the 12 glass plate calcites the average $\Delta^{44 / 42} \mathrm{Ca}$ is $-0.94 \%$, significantly more negative than reported in previous beaker experiments. For the 7 evaporating dish experiments the average is $-0.34 \%$, in the range of previous experiments.

In the glass slide experiments $\Delta^{44 / 42} \mathrm{Ca}$ varies with both temperature and zone on the plate (Figure 4$)$, but the drip rate has no effect on $\Delta^{44 / 42}$ Ca values $\left(p=0.61, r^{2}=0.01\right)$. The splash zone has more negative $\Delta^{44 / 42} \mathrm{Ca}$ than the ponded zone, with the difference in the mean $\Delta^{44 / 42} \mathrm{Ca}$ at a given temperature of 0.11 to $0.23 \%$. The temperature dependence of $\Delta^{44 / 42} \mathrm{Ca}$ is 0.005 $\pm 0.004 \% 0^{\circ} \mathrm{C}^{-1}\left(95 \%\right.$ confidence, $\left.\mathrm{p}=0.02, \mathrm{r}^{2}=0.43\right)$ for the splash zone and $0.008 \pm 0.004 \% 0^{\circ} \mathrm{C}^{-1}$ $\left(\mathrm{p}=0.002, \mathrm{r}^{2}=0.73\right)$ for the ponded zone. These slopes are effectively the same, so we also report the overall temperature dependence of $0.007 \pm 0.004 \% 0^{\circ} \mathrm{C}^{-1}\left(\mathrm{p}=0.004, \mathrm{r}^{2}=0.35\right)$.

Figures 4-6 give our results compared to previous experimental calcite precipitation data. All isotope results have been normalized by atomic mass unit difference: $\delta^{44 / 42} \mathrm{Ca}$ values by division by 2 and $\delta^{44 / 40} \mathrm{Ca}$ by division by 4 . Given the precision of these measurements, it is not apparent 
whether an equilibrium or kinetic fractionation law should be used for the normalization, so an approximation between the two scaling values (of 4.28 and 3.85 for $\delta^{44 / 40} \mathrm{Ca}$ values) is used (see Gussone et al., 2005, on this point).

Figure 5 shows the initial calcite saturation ratio $\left(\Omega_{\text {calcite }}\right)$ and calculated $\Omega_{\text {calcite_evolved }}$ for the evaporating dish and glass slide experiments. $\Omega_{\text {calcite }}$ increases from its initial value because of $\mathrm{CO}_{2}$ degassing, which is not completely counteracted by calcite precipitation. The range of $\Omega_{\text {calcite_evolved }}$ values is similar to those from Tang et al. (2008), also plotted in Figure 5.

The offset in $\mathrm{Ca}$ isotope composition between solution and precipitate of our slide experiments is greater than in all the previous calcite precipitation experiments, by $\sim 0.25 \% \mathrm{amu}^{-1}$. The evaporating dish experiments, however, have $\Delta \mathrm{Ca}$ equal to the previous work (Figures 4 and $6)$.

\section{DISCUSSION}

\subsection{Model of Calcium Carbonate Precipitation}

We present here a general overview of calcium precipitation from solution, following the model of Fantle and DePaolo (2007), which we use as the context to explain our results in the following section.

We consider two components to the system: a solution interface region and the precipitate. The interface region is the solution layer within the bulk solution immediately adjacent to the precipitate surface. Its thickness can vary with experimental setup (e.g. whether the solution is stirred or not, etc.). The precipitate is the solid phase, growing from ions from the interface region. Its growth is affected by the saturation state of the interface region (and other variables such as temperature, mineral type and surface area). Its growth rate increases with temperature and saturation state in the interface region.

We consider where and how isotopic fractionation occurs in this system (Figure 7): 
1. As the precipitate forms by addition of calcium to the surface, the lighter isotope is preferentially incorporated into the solid (with fractionation factor $\alpha_{s a}$ ). All laboratory studies of calcium precipitates have found lower precipitate isotope ratio than the solution (Gussone et al., 2003; Marriott et al., 2004; Lemarchand et al., 2004; Gussone et al., 2005; Tang et al., 2008).

2. We propose that in the opposite process, surface removal of calcium, the lighter isotope is preferentially released into solution (with fractionation factor $\alpha_{s r}$ ). There is no direct evidence for this; however, in two different natural settings (an ocean core and an aquifer), the observed net fractionation between a solution and the solid in contact for very long periods is zero (Fantle and DePaolo, 2007; Jacobson and Holmden, 2008). This is consistent with the fractionation factor for surface addition and surface removal being equal $\left(\alpha_{s a}=\alpha_{s r}\right)$ and the system having reached equilibrium, so no net fractionation has occurred. The recently published model by DePaolo (2011) is also consistent with $\alpha_{s a} \sim \alpha_{s r}$ and fits Tang et al.'s (2008) experimental data well with $\alpha_{s a}=0.9983, \alpha_{e q}=\left(\alpha_{s a} / \alpha_{s r}\right)=0.9998$ (model 2 in DePaolo, 2011).

3. During ion transport into the interface region from the bulk solution, there may be diffusive kinetic fractionation. Lighter ions or ion-complexes diffuse faster, leading to a kinetic isotopic fractionation which favours the lighter isotope. Fantle and DePaolo (2007) and Tang et al. (2008), suggest that diffusive fractionation is likely insignificant in precipitation in the ocean sedimentary environment or in well-mixed homogeneous solutions in the laboratory and we disregard this process in subsequent discussion.

We turn now to discussion of how growth rate controls the final isotopic composition of the calcite, considering the two processes of surface entrapment and depletion of the interface region.

surface entrapment: The balance of addition and removal at the precipitate surface is the net growth rate. At very low rates, where the addition flux is only just larger than removal flux, there is no net isotope fractionation, since the fractionation in either direction effectively cancels out. At higher rate, the surface addition flux is higher than the surface removal flux, so 
the fractionation from solution to solid is not canceled out by the surface removal, leading to a net fractionation from solution to solid (lower $\delta^{44 / 42}$ Ca values in the solid). This process, of ions incorporated into a precipitate before they have fully equilibrated can be termed surface entrapment (e.g. Tang et al., 2008). As the net rate increases, the net fractionation increases. At the limit of zero surface removal and infinite supply of ions in solution, the solid's isotope ratio is determined entirely by the surface addition fractionation factor $\left(\alpha_{s a}\right)$.

Ca depletion in the interface region: The characteristics of the interface region can reduce the fractionation during precipitate formation. This can occur when the ions in the interface region are used up faster than they are replenished from the bulk solution, and therefore the solid contains more of the "leftover" heavier isotope. If the interface region is thin, or with low Ca concentration, it is more likely to become depleted and total isotopic fractionation to be reduced. Conversely if the interface region is thick, or with high Ca concentration, then there is more total isotopic fractionation. At the limit of infinite thickness and ion concentration, the balance of surface addition and surface removal controls the isotopic fractionation completely.

Therefore the measured solution-to-precipitate fractionation is a combination of the net fractionation on precipitate formation, reduced to some degree by Ca depletion in the interface region. In broad terms surface entrapment favours isotope fractionation as growth rate increases, while depletion of the interface region favours fractionation as growth rate decreases. Maximum fractionation is expected at intermediate growth rates where surface entrapment can operate but the interface region is not significantly depleted (Figure 7).

Fantle and DePaolo (2007) used this two-process model to explain the differing relationships between growth rate and $\Delta \mathrm{Ca}$ in Lemarchand et al. (2004) and their own observation in the marine sedimentary environment, with the former dominantly controlled by depletion of the interface region, and the latter by surface entrapment and desorption at extremely low growth rates. Tang et al. (2008) find this model consistent with their observed relationship between growth rate and $\Delta \mathrm{Ca}$, controlled primarily by surface entrapment.

DePaolo (2011) models this explicitly in more detail, considering regimes of transport limitation 
to the surface and equilibrium or kinetic control of precipitate formation. He argues that the Tang et al. (2008) results are under surface reaction/surface entrapment control, while some of Lemarchand et al.'s (2004) data, especially the unstirred solutions, are probably transport limited, and thus have a different $\Delta \mathrm{Ca}$ and rate relationship (though the calculated rates given by Lemarchand et al., 2004, for their experiments do not allow both data sets to be reconciled).

\subsection{Explaining large isotope fractionation during cave carbonate growth}

The most striking finding of this study is that, during calcite growth at the surface of a stalagmite (i.e. the glass plate experiments), Ca isotopes are significantly more fractionated from the growth solution than in any previous calcite growth experiments. In the context of the Fantle and DePaolo (2007) model, this might be explained if the conditions of growth maximize the effect of surface entrapment, while minimizing the effect of interface-region depletion (i.e. at a position close to the trough in the "resulting fractionation" line on Figure 7). This might suggest that the growth rate in our experiments is optimal to deliver a large fractionation.

Comparison of results from all carbonate growth experiments, however, indicate that growth rate of calcite does not control $\Delta^{44 / 42} \mathrm{Ca}$ in a straightforward manner. Assessment of growth rate requires measurement of the mineral surface area on which growth is occurring. This was not possible on the glass slide set-up of this study, and is in general difficult to accurately measure in evolving precipitation experiments. Growth rate is, however, closely related to saturation state (e.g. Shiraki and Brantley, 1995) as is observed in the results of previous Ca isotope studies (e.g. Tang et al., 2008). Previous studies report the saturation state and in our experiments the initial saturation state is constrained. We also have the calculated evolved calcite saturation ratio $\left(\Omega_{\text {calcite_evolved }}\right)$ for the drip solution. We therefore use $\Omega_{\text {calcite }}$ or $\Omega_{\text {calcite_evolved }}$ (for our data) as an appropriate surrogate for growth rate. Plotting the results of this study with those of Tang et al. (2008) and Lemarchand et al. (2004) (Figure 6) demonstrates that, while saturation state is clearly a control for any one experimental set up, there is no general relationship between supersaturation $\left(\Omega_{\text {calcite }}\right)$ and $\Delta$ Ca. At low values of $\Omega_{\text {calcite }}$, for instance, $\Delta$ Ca varies over almost the full observed range. 
The lack of a single universal relationship between $\Omega_{\text {calcite }}$ and $\Delta \mathrm{Ca}$ is likely to reflect changes in the nature of the interface region from one experimental set up to another. The degree of fractionation due to surface entrapment is expected to increase monotonically as $\Omega_{\text {calcite }}$ (and therefore growth rate) increases, simply because there is less time for surface removal to reverse it. The nature of the interface region, however, can readily be different for different mineral growth environments. In the Lemarchand et al. (2004) study, for instance, calcites grown at the same saturation state showed very different $\Delta \mathrm{Ca}$ values depending on whether the solution was stirred or not. Both our results and Tang et al. (2008) have a negative dependence on the calcite saturation ratio $\left(\Omega_{\text {calcite }}\right)$, while Lemarchand et al. (2004) show a positive one (Figure 6). If we take saturation state as a rough proxy for growth rate, this suggests that our data and Tang et al.'s (2008) are in the 'surface entrapment' regime, the left side of Figure 7 panel B, while Lemarchand et al.'s (2004) is in the 'interface depletion' regime, the right side of that same Figure.

During calcite formation under a dripping solution it appears that control of the isotope ratio by interface layer depletion is significantly reduced relative to growth in a beaker, allowing the effects of surface entrapment of the light Ca isotopes to be more fully expressed. As each drop splashes onto the mineral-forming surface, it energetically refreshes the interface region with a solution at a $\Omega_{\text {calcite }}$ equal to the bulk solution. Each new drop comes into contact with the growing calcite, providing a nucleation site and allowing rapid growth. This is the situation in natural speleothems. This rapid growth drives high surface entrapment, but the replacement of the solution by a subsequent fresh drip does not allow sufficient precipitation to occur to deplete $\mathrm{Ca}$ or reduce the saturation state of the interface region.

The fact that calcites forming in the ponded zone are slightly less fractionated from the growth solution than those in the splash zone is consistent with the interface region exerting a strong control on fractionation generally. Residence times of solutions on the ponded zone are longer than those in the splash zone and the rather more quiescent conditions allow time for an interface region to become slightly more depleted in Ca. 
The slight temperature dependence of $\Delta^{44 / 42} \mathrm{Ca}$ we find in our experiments (Figure 4) can be explained by the competing effects of increased precipitation rate at higher temperature, which increases the precipitate-to-solution fractionation, counteracted by increased depletion of Ca from the interface region. Temperature itself does not straightforwardly control $\Delta^{44 / 42} \mathrm{Ca}$, and any temperature effect is small compared to other factors controlling $\Delta^{44 / 42} \mathrm{Ca}$.

In summary, the large offset between growth solution and calcite in stalagmite-analogue conditions can be explained by rapid growth at the calcite surface to cause surface entrapment of the lighter Ca isotope, accompanied by the short residence time of solution at the growing surface so that there is no chance for depletion of Ca from the interface region. The decreased significance of interface depletion means that total kinetic fractionation of Ca isotopes observed during stalagmite calcite growth is larger than that seen in other calcite growth conditions. It also suggests that surface entrapment dominates the $\mathrm{Ca}$ isotope value, in which case it is expected that the fractionation will progressively increase as the saturation state (and therefore growth rate) increases.

\subsection{Implications for use of $\mathrm{Ca}$ isotopes in speleothems}

Fractionation of $\mathrm{Ca}$ isotopes can be envisaged in three settings during stalagmite growth: during original addition of $\mathrm{Ca}$ to the karst water; during processes in the karst as the water travels to the surface of the stalagmite; and during stalagmite formation itself. In this section we consider the likely importance of these three settings for Ca isotope fractionation, and consider the possible uses of Ca isotopes in stalagmites.

Ca is initially added to karst waters by weathering of soil and by dissolution of the bedrock limestone. Increased $\mathrm{p}_{\mathrm{CO}_{2}}$ in soils lead to relatively acid conditions and it is the dissolution of bedrock that typically dominates the Ca budget. This dissolution is not normally associated with secondary mineralization and is expected to be stoichiometric so that the Ca isotope composition of the waters will be close to that of the bedrock (Tipper et al., 2008), though may be modified by vegetation to some degree (Holmden, 2009; Cenki-Tok et al., 2009). In contrast, Immenhauser et al. (2010) suggest that karst water Mg isotopes may be controlled by 
the weathering environment in the soil and then reflected in speleothems. It differs from the situation for Ca isotopes, however, where the majority of the ions come from simple bedrock dissolution with minimal isotope fractionation.

During subsequent flow of the waters through the epikarst and to the stalagmite surface, the Ca isotope composition may be altered by the effects of prior-calcite-precipitation (PCP). Such PCP will remove Ca to carbonate minerals within the epikarst or on the cave roof. Because the Ca isotope composition of the carbonates is lower than the waters, $\mathrm{PCP}$ will drive the $\mathrm{Ca}$ isotope ratio in the water higher. It is tempting to suggest that Ca isotopes might therefore be a recorder of past PCP, but the variable fractionation of $\mathrm{Ca}$ isotopes during calcite growth make it far from ideal for this purpose (and there are other proxies such as $\mathrm{Mg} / \mathrm{Ca}$ that are more strongly influenced by PCP).

During growth on the stalagmite surface, Ca isotopes will be fractionated from the solution by an amount that depends on the saturation state of the drip waters and the temperature. Results of this and previous studies indicate, however, that the temperature control on Ca isotope fractionation is too small to be significant in the cave environment so that only saturation state will be important.

Stalagmite Ca isotopes are therefore expected to reflect both PCP and saturation state of the dripwaters. In situations where PCP is absent or can be constrained, e.g. by $\mathrm{Mg} / \mathrm{Ca}$ and $\delta^{13} \mathrm{C}$ (Johnson et al., 2006), Ca isotopes may then be a proxy for past drip-water saturation state. Although perhaps seeming esoteric, an ability to assess past saturation state could prove important, particularly for $\mathrm{O}$ isotope ratios. Other proxies are also influenced by kinetic fractionation at the calcite growth surface including trace-element ratios (e.g. Sr/Ca, Tang et al., 2008) and $\delta^{18} \mathrm{O}$. Recent studies have indicated that commonly used equations relating calcite-water $\delta^{18} \mathrm{O}$ fractionation and temperature (e.g. Kim and O'Neil, 1997) are not reflective of true equilibrium fractionation (Coplen, 2007). Such work has suggested the importance of surface entrapment of ${ }^{16} \mathrm{O}$ as a kinetic effect during calcite growth (Dietzel et al., 2009; Day and Henderson, 2011) in a manner very similar to that of ${ }^{42} \mathrm{Ca}$ described in this study. The lack of 
a simple relationship between calcite $\delta^{18} \mathrm{O}$ and temperature is a serious problem for stalagmite research because $\delta^{18} \mathrm{O}$ is the most widely used proxy applied to stalagmites to reconstruct past conditions. A tool that allows assessment of the kinetic fractionation of oxygen isotopes during stalagmite growth would be of considerable use. Because both $\mathrm{Ca}$ and $\mathrm{O}$ isotopes appear to be influenced by similar surface entrapment processes, Ca isotopes may offer just such a tool. A practical application of $\mathrm{Ca}$ isotopes is therefore to check whether large variations in speleothem $\delta^{18} \mathrm{O}$ coincide with large shifts in $\delta^{44 / 42} \mathrm{Ca}$, which would suggest that a change in saturation index is partly driving the $\delta^{18} \mathrm{O}$ change, rather than reflecting a purely climatic signal. Sadly, the presence of evaporative effects in the $\delta^{18} \mathrm{O}$ values of the carbonates measured in this study (Day and Henderson, 2011) prevent a direct assessment of the relationship between $\delta^{44 / 42} \mathrm{Ca}$ and $\delta^{18} \mathrm{O}$ in this instance, but such comparison on other laboratory or natural cave carbonates will be a valuable test of the of use of Ca isotopes to correct stalagmites proxy data for the effects of kinetic fractionation and changes in saturation state.

\section{CONCLUSIONS}

We have measured the calcium isotope ratios of calcite precipitated in the laboratory in a speleothem-like drip experiment. There is a small temperature-dependence of $0.007 \% 0^{\circ} \mathrm{C}^{-1}$, in accord with previous studies. The solution-to-precipitate fractionation is about $0.5 \% \mathrm{amu}^{-1}$, generally almost double that found in beaker-type calcite precipitation experiments. We attribute this large fractionation to kinetic effects during rapid precipitate formation by surface entrapment of lighter $\mathrm{Ca}$, while depletion of $\mathrm{Ca}$ ions from the interface region near the calcite surface is minimized. Calcium isotopes may be useful for speleothem research as a control on solution saturation state, which may help constrain non-equilibrium $\delta^{18} \mathrm{O}$ effects. 
Amini M., Eisenhauer A., Böhm F., Holmden C., Kreissig K., Hauff F., and Jochum K. P. (2009) Calcium isotopes $\left(\delta^{44 / 40} \mathrm{Ca}\right)$ in MPI-DING reference glasses, USGS rock powders and various rocks: Evidence for Ca isotope fractionation in terrestrial silicates. Geostand. Geoanal. Res. 33, 231-247.

Ayalon A., Bar-Matthews M., and Kaufman A. (1999) Petrography, strontium, barium and uranium concentrations and strontium and uranium isotope ratios in speleothems as paleoclimatic proxies: Soreq Cave, Israel. The Holocene 9, 715-722.

Bar-Mathews M. and Ayalon A. (1997) Late Quaternary paleoclimate in the Eastern Mediterranean region from stable isotope analysis of speleothems at Soreg Cave, Israel. Quaternary Res. 47, 155-168.

Cenki-Tok B., Chabaux F., Lemarchand D., Schmitt A. D., Pierret M. C., Viville D., Bagard M. L., and Stille P. (2009) The impact of water-rock interaction and vegetation on calcium isotope fractionation in soil- and stream waters of a small, forested catchment (the Strengbach case). Geochim. Cosmochim. Acta 73, 2215-2228.

Chu N. C., Henderson G. M., Belshaw N. S., and Hedges R. E. M. (2006) Establishing the potential of $\mathrm{Ca}$ isotopes as proxy for consumption of dairy products. Appl. Geochem. 21, $1656-1667$.

Clementz M. T., Holden P., and Koch P. L. (2003) Are calcium isotopes a reliable monitor of trophic level in marine settings? Int. J. Osteoarch. 13, 29-36.

Coplen T. B. (2007) Calibration of the calcite-water oxygen-isotope geothermometer at Devils Hole, Nevada, a natural laboratory. Geochim. Cosmochim. Acta 71, 3948-3957.

Day C. C. and Henderson G. M. (2011) Oxygen isotopes in calcite grown under cave-analogue conditions. Geochim. Cosmochim. Acta in review.

DePaolo, D. J. (2011) Surface kinetic model for isotopic and trace element fractionation during precipitation of calcite from aqueous solutions. Geochim. Cosmochim. Acta 75, 1039-1056. 
Dietzel M., Tang J. W., Leis A., and Kohler S. J. (2009) Oxygen isotopic fractionation during inorganic calcite precipitation - effects of temperature, precipitation rate and $\mathrm{pH}$. Chem. Geol. 268, 107-115.

Dreybrodt W. and Scholz D. (2011) Climate dependence of stable carbon and oxygen isotope signals recorded in speleothems: from soil water to speleothem calcite. Geochim. Cosmochim. Acta 75, 734-752.

Ewing S. A., Yang W., DePaolo D. J., Michalski G., Kendall C., Stewart B. W., Thiemens M., and Amundson R. (2008) Non-biological fractionation of stable Ca isotopes in soils of the Atacama Desert, Chile. Geochim. Cosmochim. Acta 72, 1096-1110.

Fairchild I. J. and Treble P. C. (2009) Trace elements in speleothems as recorders of environmental change. Quaternary Sci. Rev. 28, 449-468.

Fantle M. S. and DePaolo D. J. (2005) Variations in the marine Ca cycle over the past 20 million years. Earth Planet. Sci. Lett. 237, 102-117.

Fantle M. S. and DePaolo D. J. (2007) Ca isotopes in carbonate sediment and pore fluid from ODP Site 807A: The $\mathrm{Ca}^{2+}(\mathrm{aq})$-calcite equilibrium fractionation factor and calcite recrystallization rates in Pleistocene sediments. Geochim. Cosmochim. Acta 71, 2524-2546.

Farkaš J., Bohm F., Wallmann K., Blenkinsop J., Eisenhauer A., van Geldern R., Munnecke A., Voigt S., and Veizer J. (2007a) Calcium isotope record of Phanerozoic oceans: Implications for chemical evolution of seawater and its causative mechanisms. Geochim. Cosmochim. Acta $71,5117-5134$.

Farkaš J., Buhl D., Blenkinsop J., and Veizer J. (2007b) Evolution of the oceanic calcium cycle during the late Mesozoic: Evidence from $\delta^{44 / 40} \mathrm{Ca}$ of marine skeletal carbonates. Earth Planet. Sci. Lett. 253, 96-111.

Fleitmann D., Burns S. J., Mudelsee M., Neff U., Kramers J., and Mangini A. (2003) Holocene forcing of the Indian Monsoon recorded in a stalagmite from Southern Oman. Science 300, $1737-1739$. 
Griffith E. M., Schauble E. A., Bullen T. D., and Paytan A. (2008) Characterization of calcium isotopes in natural and synthetic barite. Geochim. Cosmochim. Acta 72, 5641-5658.

Gussone N., Böhm F., Eisenhauer A., Dietzel M., Heuser A., Teichert B. M. A., Reitner J., Worheide G., and Dullo W. C. (2005) Calcium isotope fractionation in calcite and aragonite. Geochim. Cosmochim. Acta 69, 4485-4494.

Gussone N., Eisenhauer A., Heuser A., Dietzel M., Bock B., Böhm F., Spero H. J., Lea D. W., Bijma J., and Nägler T. F. (2003) Model for kinetic effects on calcium isotope fractionation $\left(\delta^{44} \mathrm{Ca}\right)$ in inorganic aragonite and cultured planktonic foraminifera. Geochim. Cosmochim. Acta 67, 1375-1382.

Heuser, A. and Eisenhauer, A. (2008) The calcium isotope composition $\left(\delta^{44 / 40} \mathrm{Ca}\right)$ of NIST SRM 915b and NIST SRM 1486. Geostand. Geoanal. Res. 32, 311-315.

Hippler D., Schmitt A.-D., Gussone N., Heuser A., Stille P., Eisenhauer A., and Nägler T. F. (2003) The calcium isotope composition of various reference materials and seawater. Geostand. Geoanal. Res. 27, 13-19.

Hirata T., Tanoshima M., Suga A., Tanaka Y., Nagata Y., Shinohara A., and Chiba M. (2008) Isotopic analysis of calcium in blood plasma and bone from mouse samples by multiple collector-ICP-mass spectrometry. Anal. Sci. 24, 1501-1507.

Holmden C. (2009) Ca isotope study of Ordovician dolomite, limestone, and anhydrite in the Williston Basin: Implications for subsurface dolomitization and local Ca cycling. Chem. Geol. 268, 180-188.

Hu C., Henderson G. M., Huang J., Xie S., Sun Y., and Johnson K. R. (2008) Quantification of Holocene Asian monsoon rainfall from spatially separated cave records. Earth Planet. Sci. Lett. 266, 221-232.

Immenhauser A., Buhl D., Richter D., Niedermayr A., Riechelmann D., Dietzel M., and Schulte U. (2010) Magnesium-isotope fractionation during low-mg calcite precipitation in a limestone cave - field study and experiments. Geochim. Cosmochim. Acta 74, -4364 . 
Jacobson A. D. and Holmden C. (2008) $\delta^{44}$ Ca evolution in a carbonate aquifer and its bearing on the equilibrium isotope fractionation factor for calcite. Earth Planet. Sci. Lett. 270, 349-353.

Jahne B., Heinz G., and Dietrich W. (1987) Measurement of the diffusion coefficients of sparingly soluble gases in water. J. Geophys. Res. - Oceans 92, 10767-10776.

Johnson K. R., Hu C., Belshaw N. S., and Henderson G. M. (2006) Seasonal trace-element and stable-isotope variations in a Chinese speleothem: The potential for high-resolution paleomonsoon reconstruction. Earth Planet. Sci. Lett. 244, 394-407.

Kim S. T. and O'Neil J. R. (1997) Equilibrium and nonequilibrium oxygen isotope effects in synthetic carbonates. Geochim. Cosmochim. Acta 61, 3461-3475.

Lachniet M. S. (2009) Climatic and environmental controls on speleothem oxygen-isotope values. Quaternary Sci. Rev. 28, 412-432.

Lemarchand D., Wasserburg G., and Papanastassiou D. (2004) Rate-controlled calcium isotope fractionation in synthetic calcite. Geochim. Cosmochim. Acta 68, 4665-4678.

Lin,Y.-P., and Singer P.C. (2005) Effects of seed material and solution composition on calcite precipitation. Geochim. Cosmochim. Acta 69, 4495-4504.

Marriott C. S., Henderson G. M., Belshaw N. S., and Tudhope A. W. (2004) Temperature dependence of $\delta^{7} \mathrm{Li}, \delta^{44} \mathrm{Ca}$ and $\mathrm{Li} / \mathrm{Ca}$ during growth of calcium carbonate. Earth Planet. Sci. Lett. 222, 615-624.

McDermott F. (2004) Palaeo-climate reconstruction from stable isotope variations in speleothems: a review. Quaternary Sci. Rev. 23, 901-918.

Mickler P. J., Stern, L. A., and Banner, J. L. (2006) Large kinetic isotope effects in modern speleothems Geol. Soc. Amer. Bull. 118, 65-81.

Nägler T. F., Eisenhauer A., Müller A., Hemleben C., and Kramers J. (2000) The $\delta^{44}$ Catemperature calibration on fossil and cultured Globigerinoides sacculifer: New tool for reconstruction of past sea surface temperatures. Geochem. Geophys. Geosyst. 1, 2000GC000,091. 
Page B. D., Bullen T. D., and Mitchell M. J. (2008) Influences of calcium availability and tree species on Ca isotope fractionation in soil and vegetation. Biogeochemistry 88, 1-13.

Parkhurst D.L. and Appelo, C.A. (1999) User's guide to PHREEQC (version 2): a computer program for speciation, batch-reaction, one-dimensional transport, and inverse geochemical calculations. Vol. 99-4259. Denver, Colorado. U.S. Department of the Interior, U.S. Geological Survey.

Reynard L. M., Henderson G. M., and Hedges R. E. M. (2010) Calcium isotope ratios in animal and human bone. Geochim. Cosmochim. Acta 74, 3735-3750.

Schmitt A.D., Chabaux F., and Stille P. (2003) The calcium riverine and hydrothermal isotopic fluxes and the oceanic calcium mass balance. Earth Planet. Sci. Lett. 213, 503-518.

Shiraki R. and Brantley S. L. (1995) Kinetics of near-equilibrium calcite precipitation at $100^{\circ} \mathrm{C}$ - an evaluation of elementary reaction-based and affinity-based rate laws. Geochim. Cosmochim. Acta 59, 1457-1471.

Sime N. G., De La Rocha C. L., and Galy A. (2005) Negligible temperature dependence of calcium isotope fractionation in 12 species of planktonic foraminifera. Earth Planet. Sci. Lett. 232, 51-66.

Sime N. G., De La Rocha C. L., Tipper E. T., Tripati A., Galy A., and Bickle M. J. (2007) Interpreting the $\mathrm{Ca}$ isotope record of marine biogenic carbonates. Geochim. Cosmochim. Acta 71, 3979-3989.

Skulan J., Bullen T., Anbar A. D., Puzas J. E., Shackelford L., LeBlanc A., and Smith S. M. (2007) Natural calcium isotopic composition of urine as a marker of bone mineral balance. Clin. Chem. 53, 1155-1158.

Skulan J. and DePaolo D. J. (1999) Calcium isotope fractionation between soft and mineralized tissues as a monitor of calcium use in vertebrates. Proc. Nat. Acad. Sci. USA 96, 13,709$13,713$. 
Skulan J., DePaolo D. J., and Owens T. L. (1997) Biological control of calcium isotopic abundances in the global calcium cycle. Geochim. Cosmochim. Acta 61, 2505-2510.

Steefel C. I, and Van Cappellen P. (1990) A new kinetic approach to modeling water-rock interaction: The role of nucleation, precursors, and Ostwald ripening. Geochim. Cosmochim. Acta 54, 2657-2677.

Stumm W., and Morgan J. J. (1996) Aquatic chemistry: chemical equilibria and rates in natural waters. 3rd edition. New York: Wiley.

Tang J., Dietzel M., Böhm F., Köhler S. J., and Eisenhauer A. (2008) $\mathrm{Sr}^{2+} / \mathrm{Ca}^{2+}$ and ${ }^{44} \mathrm{Ca} /{ }^{40} \mathrm{Ca}$ fractionation during inorganic calcite formation: II. Ca isotopes. Geochim. Cosmochim. Acta 72, 3733-3745.

Teichert B. M., Gussone N., and Torres M. E. (2009) Controls on calcium isotope fractionation in sedimentary porewaters. Earth Planet. Sci. Lett. 279, 373-382.

Tipper E. T., Galy A., and Bickle M. J. (2006) Riverine evidence for a fractionated reservoir of $\mathrm{Ca}$ and $\mathrm{Mg}$ on the continents: Implications for the oceanic Ca cycle. Earth Planet. Sci. Lett 247, 267-279.

Tipper E. T., Galy A., and Bickle M. J. (2008) Calcium and magnesium isotope systematics in rivers draining the Himalaya-Tibetan-Plateau region: Lithological or fractionation control? Geochim. Cosmochim. Acta 72, 1057-1075.

Wang Y. L., Cheng H., Edwards R. L., Zn Z. S., Wu J. Y., Shen C. C., and Dorale J. A. (2001) A high-resolution absolute-dated late Pleistocene monsoon record from Hulu Cave, China. Science 294, 2345-2348.

Wiedner E., Scholz D., Mangini A., Polag D., Muhlinghaus C., and Segl M. (2008) Investigation of the stable isotope fractionation in speleothems with laboratory experiments. Quatern. Int. $187,15-24$.

Zhu P. and Macdougall J. D. (1998) Calcium isotopes in the marine environment and the oceanic calcium cycle. Geochim. Cosmochim. Acta 62, 1691-1698. 
Table 1: Initial solution compositions $(\mathrm{mmol} / \mathrm{L})$ for the glass plate and evaporating dish experiments

\begin{tabular}{|c|c|c|c|c|c|}
\hline \multirow[b]{2}{*}{$\mathrm{T}\left({ }^{\circ} \mathrm{C}\right)$} & \multicolumn{4}{|c|}{ Plate } & \multirow{2}{*}{$\begin{array}{c}\text { Dish } \\
10,20,25,30\end{array}$} \\
\hline & 7 & 15 & 25 & 35 & \\
\hline $\mathrm{pH}$ & $6.9 \pm 0.2$ & $6.9 \pm 0.1$ & $6.8 \pm 0.2$ & $6.9 \pm 0.1$ & $5.5 \pm 0.2$ \\
\hline$[\mathrm{Li}]$ & $1.4 \times 10^{-3}$ & $1.2 \times 10^{-3}$ & $1.0 \times 10^{-3}$ & $8.7 \times 10^{-4}$ & $1.4 \times 10^{-3}$ \\
\hline$[\mathrm{Na}]$ & $4.3 \times 10^{-2}$ & $3.7 \times 10^{-2}$ & $3.1 \times 10^{-2}$ & $2.6 \times 10^{-2}$ & $4.4 \times 10^{-2}$ \\
\hline$[\mathrm{Mg}]$ & $3.1 \times 10^{-1}$ & $2.6 \times 10^{-1}$ & $2.2 \times 10^{-1}$ & $1.9 \times 10^{-1}$ & $6.5 \times 10^{-1}$ \\
\hline$[\mathrm{P}]$ & & & & & $5.8 \times 10^{-3}$ \\
\hline$[\mathrm{Ca}]$ & 4.0 & 3.4 & 2.9 & 2.4 & 6.7 \\
\hline [Co] & & & $1.2 \times 10^{-4}$ & $1.0 \times 10^{-4}$ & $6.8 \times 10^{-6}$ \\
\hline$[\mathrm{Sr}]$ & $4.8 \times 10^{-3}$ & $4.0 \times 10^{-3}$ & $3.4 \times 10^{-3}$ & $2.9 \times 10^{-3}$ & $5.5 \times 10^{-3}$ \\
\hline$[\mathrm{Cd}]$ & $8.9 \times 10^{-5}$ & $7.5 \times 10^{-5}$ & $6.3 \times 10^{-5}$ & $5.4 \times 10^{-5}$ & $8.9 \times 10^{-5}$ \\
\hline$[\mathrm{Ba}]$ & & & $1.3 \times 10^{-2}$ & $1.1 \times 10^{-2}$ & $2.3 \times 10^{-2}$ \\
\hline$[\mathrm{U}]$ & $6.5 \times 10^{-5}$ & $5.5 \times 10^{-5}$ & $4.6 \times 10^{-5}$ & $3.9 \times 10^{-5}$ & $6.7 \times 10^{-5}$ \\
\hline
\end{tabular}

All solution measurements relate to the starting solution, before degassing occurs in the precipitation flask. Empty cells for a given trace element indicate that the given element was not included in that specific experiment. All errors are \pm 2 s.d.

Table 2: Solution chemistry in calcite precipitation experiments

\begin{tabular}{llccc}
\hline & $\begin{array}{l}{[\mathrm{Ca}]_{i}} \\
(\mathrm{mM})\end{array}$ & $\Omega_{\text {calcite }}$ & $\begin{array}{c}\text { saturation } \\
\text { index }\end{array}$ & $\begin{array}{c}\text { ionic } \\
\text { strength }(\mathrm{mM})\end{array}$ \\
\hline present work initial solutions (slides) & $2.4-4.0$ & 2.2 & 0.34 & $5-8$ \\
present work initial solutions (dish) & 6.7 & $0.22-1.0$ & $-0.65-0.0$ & 14 \\
Lemarchand et al. (2004) A & 150 & $4-105$ & $0.60-2.02$ & 850 \\
Lemarchand et al. (2004) B & 15 & $3-20$ & $0.48-1.30$ & 450 \\
Tang et al. (2008) & 10 & $3.2-17.0$ & $0.51-1.23$ & 36 \\
Marriott et al. (2004) & $240^{a}$ & & & 720 \\
\hline
\end{tabular}

a $470 \mathrm{mM} \mathrm{CaCl} 2$ added to this initial solution at rate of $200 \mu \mathrm{L} / \mathrm{min}$ 


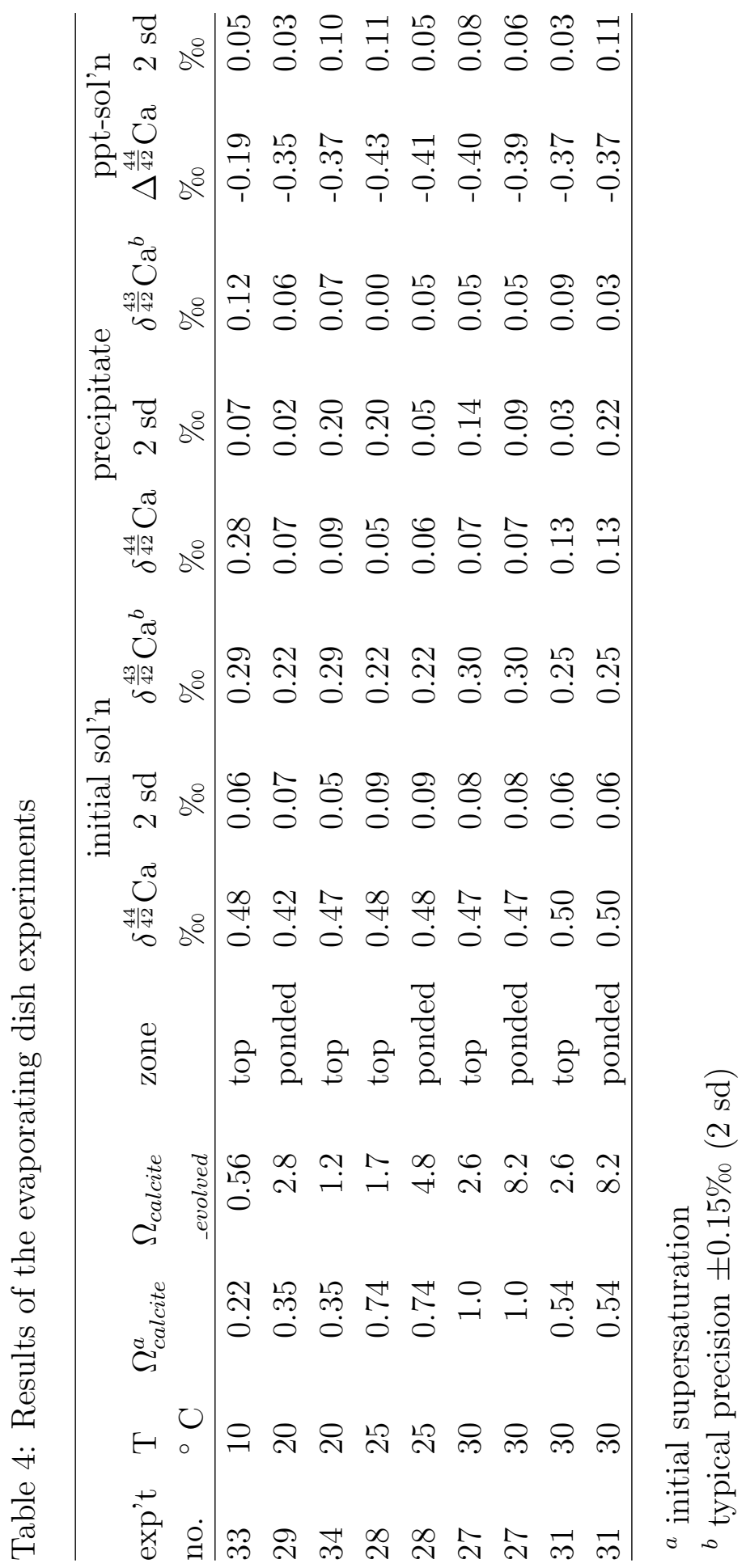


Figure 1: Diagram of the experimental apparatus, discussed in more detail in Day and Henderson (2011).

Figure 2: Plan and profile views of the glass slide and evaporating dish used as precipitation substrates.

Figure 3: Scanning electron micrographs of a typical seeded glass plate (at left) and a typical precipitate in the splash zone during glass slide growth (at right; experiment no. 49, run at drip rate $1.6 \mathrm{drips} / \mathrm{min}, 35^{\circ} \mathrm{C}$.)

Figure 4: $\triangle \mathrm{Ca}$ versus temperature for calcite normalized by mass difference for the present work and previous beaker experiments. Data are from the present work, Marriott et al. (2004), Lemarchand et al. (2004), and Tang et al. (2008).

Figure 5: $\Delta$ Ca versus calcite saturation ratio $\left(\Omega_{\text {calcite }}\right)$ for calcite normalized by mass difference for the present work and Tang et al. (2008). The grey shading shows the change in $\Omega_{\text {calcite }}$ from the initial solution (far left of each bar) to the calculated $\Omega_{\text {calcite_evolved }}$ value (coloured data point, with the error bars showing the minimum and maximum estimates for calcite evolved; see the Appendix for calculation details).

Figure 6: $\Delta$ Ca versus calcite saturation ratio $\left(\Omega_{\text {calcite }}\right)$ normalized by mass difference for the present work and previous beaker experiments. Our data are plotted vs. $\Omega_{\text {calcite_evolved }}$ (same coloured points as in Figure 5). The regression lines for Lemarchand et al. (2004) are for solution A only, while that for Tang et al. (2008) is for all temperatures together. Individual experiments have $\Delta$ Ca correlations with $\Omega_{\text {calcite }}$, but there is no overall correlation for all experiments.

Figure 7: A cartoon representation of the Fantle and DePaolo (2007) model used to interpret the data of this study. Panel A illustrates how addition and removal of calcium at the calcite surface have similar fractionation factors, but can still generate an overall fractionated calcite value if addition is quicker than removal. The interface region is replenished by mixing from the rest of the solution, but if this mixing is slow compared to growth, depletion of Ca in the interface region serves to reduce total fractionation in the calcite. Panel B is a graph that shows schematically how the two effects of surface entrapment (i.e. addition faster than removal) and interface region depletion interact to control $\mathrm{Ca}$ isotope fractionation with changing growth rate. The exact form of this curve depends on the nature of the interface region in the specific growth conditions and can vary significantly with growth environment. 
We provide here details of the calculation of the change in solution calcite saturation ratio, $\Omega_{\text {calcite_evolved }}$, from the initial value for our drip solutions. $\Omega_{\text {calcite }}$ applicable to the drip solution flowing over stalactite and stalagmite samples is extremely dynamic due to rapid $\mathrm{CO}_{2}$-degassing and subsequent calcite precipitation as drip solution enters the cave. The saturation ratios applicable to these cave-analogue experiments are therefore calculated from the kinetics of $\mathrm{CO}_{2(a q)}$-degassing and of calcite precipitation. Three stages are considered: i) $\mathrm{CO}_{2(a q)}$-degassing during drip formation (there was no calcite precipitation during this stage), ii) $\mathrm{CO}_{2(a q)}$-degassing and calcite precipitation within the splash zone and iii) $\mathrm{CO}_{2(a q)}$-degassing and calcite precipitation within the ponded zone (Figure 2). The drip forms from an upturned pipettor tip (Day and Henderson, 2011) akin to a soda straw tube in the cave environment and therefore with $\mathrm{CO}_{2(a q)}$-degassing approximated by diffusion from a spherical drop with radius $r$ (Dreybrodt and Scholz, 2011). The time constant for physical degassing from this spherical drop is given by $\tau_{\text {out drip }}=\frac{4 * r^{2}}{\pi^{2} D_{m}}$ (Dreybrodt and Scholz, 2011), where $D_{m}$ is the coefficient of molecular diffusion for $\mathrm{CO}_{2(a q)}$ with values from Jahne et al. (1987). An exponential decay equation describes the change in $\left[\mathrm{CO}_{2(a q)}\right]$ or $\left[\mathrm{HCO}_{3}^{-}\right]$over time $t$ :

$$
\Delta[X](t)=\left(C_{0} X-C_{e q} X\right) *(\exp (-t / \tau)-1)
$$

where $C_{0} X$ denotes initial concentration and $C_{e q} X$ equilibrium concentration of species $X$ (either $\mathrm{CO}_{2(a q)}$ or $\mathrm{HCO}_{3}^{-}$) and $\tau$ is the time constant ( $\tau_{\text {out drip }}$ applies to degassing from a spherical drip, $\tau_{\text {out film }}$ applies to degassing from a thin film solution, and $\tau_{p}$ applies to calcite precipitation).

On impacting the glass plate, the solution takes the form of a thin sheet, of thickness $\delta$, with physical degassing of $\mathrm{CO}_{2(a q)}$ governed by molecular diffusion and time constant $\tau_{\text {out film }}=\frac{4 * \delta^{2}}{\pi^{2} D_{m}}$ (Dreybrodt and Scholz, 2011). The concentration of $C O_{2(a q)}$ decreases according to the same exponential decay equation 1. 
Bicarbonate and calcium loss from calcite precipitation are based on the reaction for calcite precipitation $\mathrm{Ca}^{2+}+2 \mathrm{HCO}_{3}^{-} \leftrightharpoons \mathrm{CaCO}_{3}+\mathrm{H}_{2} \mathrm{O}+\mathrm{CO}_{2}$. Bicarbonate concentration decays exponentially according to equation 1 , where $\tau_{p}=\frac{\delta}{\alpha_{p}}$ is the time constant for calcite precipitation and $\alpha_{p}$ is the kinetic constant in $\mathrm{cm} \cdot \mathrm{s}^{-1}$ (Dreybrodt and Scholz, 2011). For calcium,

$$
\Delta\left[C a^{2+}\right](t)=\frac{\Delta\left[H C O_{3}^{-}\right](t)}{2}
$$

Time intervals are established from the residence time of solution on the glass plate:

$$
\text { solution residence time }=\frac{\text { plate solution volume }(m L)}{\text { flow rate }\left(m L * s^{-1}\right)}
$$

Measured values provide $t$ for the whole plate. Splash zone residence time is taken as the drip interval. Although the drip interval provides a suitable approximation, solution-behaviour within the splash zone is complex. At the plate center, some solution flows down-plate before the arrival of the next drip. Further from the center, solution is supplied as micro-droplets formed on impact of the drop with the plate. Replacement of these droplets is less frequent and therefore residence time increases with greater distance from the center. In assessing the uncertainty on $\Omega_{\text {calcite_evolved }}$, the measured solution residence time in the splash zone was allowed to vary by a factor of six to account for this greater uncertainty.

The initial distribution of species in solution (prior to degassing) is established using PHREEQC (Parkhurst and Appelo, 1999). As the solution degases and flows down the plate, changes in $\left[\mathrm{CO}_{2(a q)}\right],\left[\mathrm{HCO}_{3}^{-}\right]$and $\left[\mathrm{Ca}^{2+}\right]$ are calculated for each time step (one second intervals) using equations 1 and 2 and the appropriate time constants $\tau$. These values are then input into PHREEQC to update the distribution of species and to calculate $\Omega_{\text {calcite_evolved }}$ for each time step. The splash zone $\Omega_{\text {calcite_evolved sz }}$ is the average saturation ratio for all one second time steps until the drip interval. The ponded zone $\Omega_{\text {calcite_evolved } p z}$ is the average saturation ratio between the drip interval and the whole plate solution residence time.

Differences between modelled and measured amounts of calcite precipitation are corrected to 
produce $\Omega_{\text {calcite_evolved }}$ applicable to these exact growth conditions. This greatly reduces uncertainty on $\Omega_{\text {calcite_evolved }}$. Assessing the uncertainty of calculated $\Omega_{\text {calcite_evolved }}$ (error bars on Figure 5) is established by taking the extreme scenarios leading to low and high $\Omega_{\text {calcite_evolved. Low end }} \Omega_{\text {calcite_evolved }}$ values are attained with high solution thickness, high cave $\mathrm{pCO}_{2}$, long solution residence and the high-end measurement of percent calcite precipitated. High end $\Omega_{\text {calcite_evolved }}$ values are obtained with low solution thickness, low cave $p \mathrm{CO}_{2}$, short solution residence time and the low-end measurement of percent calcite precipitated. All input parameters for these calculations are provided in Tables A1 and A2. 


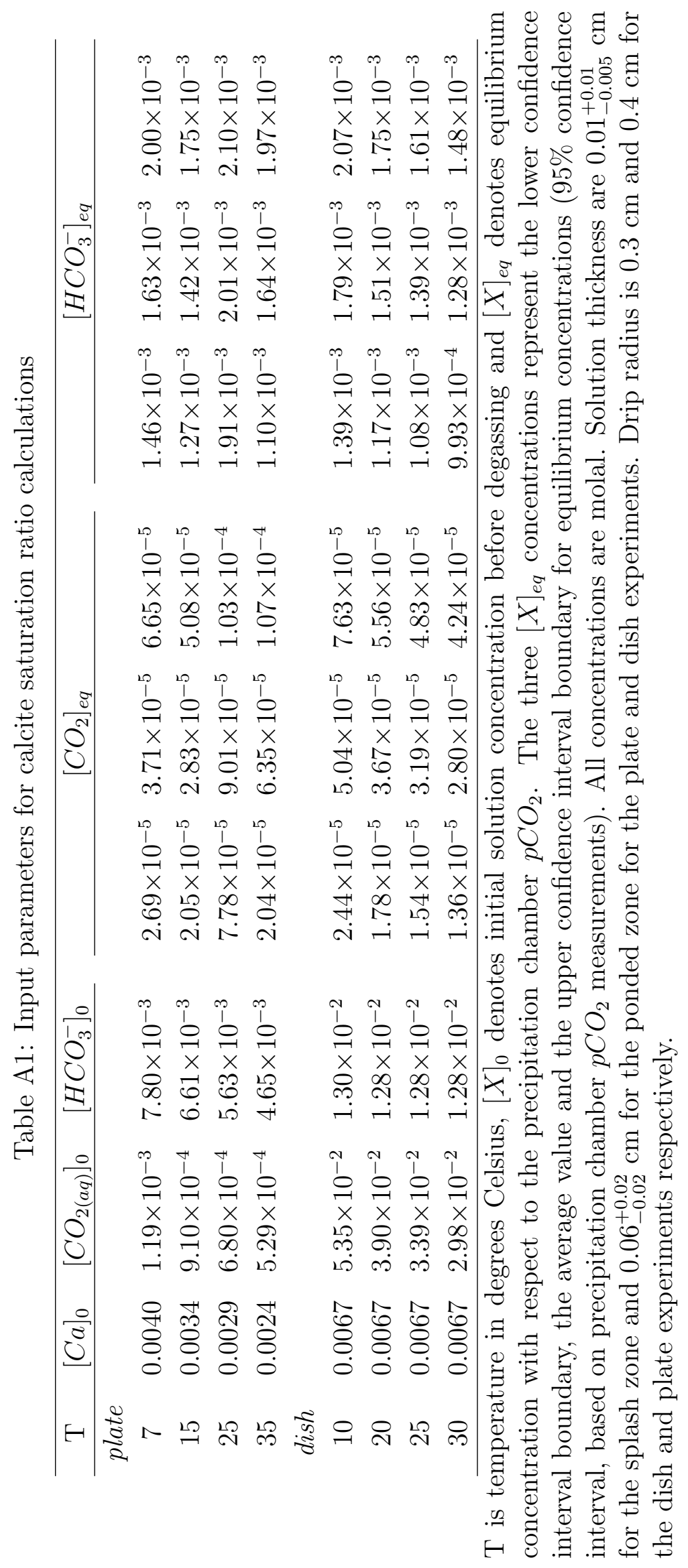


Table A2: Solution residence time for the glass plate and the evaporating dish experiments

\begin{tabular}{|c|c|c|c|c|c|c|}
\hline $\begin{array}{l}\text { drip rate } \\
\text { (drips/min) }\end{array}$ & SZ resi & $\begin{array}{l}\text { den } \\
(\mathrm{s})\end{array}$ & ce time & WP res & $\begin{array}{l}\text { idenc } \\
(\mathrm{s})\end{array}$ & e time \\
\hline \multicolumn{7}{|l|}{ plate } \\
\hline 1.6 & 19 & 38 & 114 & & 462 & \\
\hline 5.8 & 5 & 10 & 30 & & 107 & \\
\hline 10.4 & 3 & 6 & 18 & & 70 & \\
\hline \multicolumn{7}{|l|}{ dish } \\
\hline 13.7 & 2.5 & 5 & 15 & 11 & 15 & 19 \\
\hline
\end{tabular}

The middle splash zone (SZ) value is the drip interval, used to approximate residence time. The lower and upper values are half and three times the drip interval respectively, used to assess uncertainty in $\Omega_{\text {calcite_evolved }}$ associated with the dynamic nature of solution flow within the splash zone. Whole plate solution residence times (WP) are measured values, uncertainty is only included for the dish experiments, where this can affect the range of possible $\Omega_{\text {calcite_evolved }}$. 